\title{
Raising HDL cholesterol in women
}

This article was published in the following Dove Press journal:

International Journal of Women's Health

17 November 2009

Number of times this article has been viewed

\section{Danny J Eapen' \\ Girish L Kalra' \\ Luay Rifai' \\ Christina A Eapen ${ }^{2}$ \\ Nadya Merchant' \\ Bobby V Khan'}

'Emory University School of Medicine, Atlanta, GA, USA; ${ }^{2}$ University of South Florida School of Medicine, Tampa, FL, USA
Correspondence: Bobby V Khan 69 Jesse Hill Jr Dr SE, Atlanta, GA 30303, USA

$\mathrm{Tel}+\mathrm{I} 4046164440$

Fax +I 4046164400

Email bkhan@emory.edu
Abstract: High-density lipoprotein cholesterol (HDL-C) concentration is essential in the determination of coronary heart disease (CHD) risk in women. This is especially true in the postmenopausal state, where lipid profiles and CHD risk mimic that of age-matched men. Thus, interventions designed to reduce CHD risk by raising HDL-C levels may have particular significance during the transition to menopause. This review discusses HDL-C-raising therapies and the role of HDL in the primary prevention of CHD in women. Lifestyle-based interventions such as dietary change, aerobic exercise regimens, and smoking cessation are initial steps that are effective in raising HDL-C, and available data suggest women respond similarly to men with these interventions. When combined with pharmacotherapy, the effects of these lifestyle alterations are further amplified. Though studies demonstrating gender-specific differences in therapy are limited, niacin continues to be the most effective agent in raising HDL-C levels, especially when used in combination with fibrate or statin therapy. Emerging treatments such as HDL mimetic therapy show much promise in further raising HDL-C levels and improving cardiovascular outcomes.

Keywords: high-density lipoprotein, HDL, women, cholesterol, heart disease

\section{Introduction}

Coronary heart disease (CHD) remains the leading cause of death in American women and is responsible for more deaths in women than all forms of cancer combined. CHD now ranks first among all disease categories in hospital discharge diagnoses for women, and it continues to pose a greater diagnostic challenge in women than men. ${ }^{1}$

The assessment of CHD risk and its subsequent management relies heavily on lipid and lipoprotein levels. HMG-CoA reductase inhibitor (statin) therapy, aimed primarily at decreasing low-density lipoprotein cholesterol (LDL-C) levels, remains at the forefront in primary and secondary CHD prevention in both sexes. However, approximately $65 \%$ to $75 \%$ of cardiovascular events still occur despite statin use. ${ }^{2}$ There is a great need for other target therapies, most notably high-density lipoprotein cholesterol (HDL-C) raising strategies, to further prevent CHD.

In several studies, HDL-C concentration was found to be the best predictor of coronary heart disease risk in women. ${ }^{3-5}$ The Framingham Heart Study showed women in the lowest quintile of HDL-C to have a relative risk of CHD three times higher than those in the highest quintile. ${ }^{6}$ The current body of literature, however, is limited with regard to HDL-C-raising therapies specifically for women.

This review discusses the mechanisms by which HDL exerts its favorable cardiovascular effects and examines the role HDL plays in the primary prevention 
of CHD in women. Moreover, HDL-C concentration will be explored as a therapeutic target as current, as well as emerging, HDL-C-raising therapies in women are evaluated. We reviewed recent and past literature using Ovid Medline and PubMed databases (National Library of Medicine, Bethesda, MD, USA) from 1955 to present. Search terms used included HDL, cholesterol, lipids, metabolism, pathogenesis, women, gender, sex, coronary heart disease, exercise, and estrogen.

\section{HDL metabolism}

The mature HDL particle is comprised of a cholesterol core surrounded by an outer shell of phospholipids and apolipoproteins. Through a mechanism known as reverse cholesterol transport, the particle promotes the efflux of surplus cellular cholesterol from peripheral tissues and delivers it to the liver for eventual excretion in the bile. This "removal" of excess cholesterol from cells and lipid-containing macrophages represents much of the proposed atheroprotective benefit of HDL. ${ }^{7-9}$

HDL assembly begins with the secretion of lipid-poor apolipoprotein A-I (apoA-I) from the liver and intestine. In reverse cholesterol transport, the nascent particle interacts with ATP-binding cassette transporter 1 (ABCA1) to acquire excess cholesterol from cells and atherosclerotic plaques, forming an early HDL particle known as pre-beta-HDL. Alternatively, it may acquire cholesterol released from lipoprotein lipase-mediated lipolysis of triglyceride-rich very low LDL (VLDL) and chylomicrons. Free cholesterol in pre-beta-HDL is subsequently esterified by apoA-I-mediated activation of the enzyme lecithin-cholesterol acyltransferase (LCAT), resulting in the formation of mature alpha-HDL particles. ${ }^{8,10}$

Cholesterol is subsequently transferred to sites such as the liver through various mechanisms. In one, HDL-C is selectively transported into hepatocytes and cells of steroidogenic tissues such as the ovary and the adrenal gland via the Scavenger receptor class B, type I (SR-B1). ${ }^{10}$ Potential fates for this cholesterol include excretion through bile or storage and utilization for purposes such as hormone synthesis. Cholesterol may alternately be transferred to other lipoprotein particles via lipid transfer proteins such as the cholesterol ester transfer protein (CETP), which mediates the transfer of cholesterol esters from HDL particles to less favorable VLDL, intermediate-density lipoprotein (IDL), and LDL particles. ${ }^{11}$ Inhibition of CETP as a method for raising HDL-C will be discussed later in this review.

Aside from its role in reverse cholesterol transport, HDL has been shown to exert a variety of other anti-inflammatory actions in the laboratory setting. HDL inhibits the rate of macrophage-induced oxidation of LDL, ${ }^{12}$ and it also inhibits oxidized LDL-induced upregulation of cell adhesion molecules. ${ }^{13}$ HDL stimulates the synthesis of the eicosanoid prostacyclin $\left(\mathrm{PGI}_{2}\right)$, which in turn inhibits platelet activation and vascular smooth muscle cell growth and migration. ${ }^{14}$ $\mathrm{PGI}_{2}$ also inhibits endothelial cell apoptosis and decreases complement activation. ${ }^{15}$ Additionally, HDL has been shown to increase the expression and activity of endothelial nitric oxide synthase (eNOS), thereby potentially exerting favorable effects on coronary and peripheral arterial endothelial function. ${ }^{16,17}$ Though their applicability outside the laboratory setting remains uncertain, these encouraging biologic properties of the HDL particle suggest additional antiatherogenic influence independent of HDL's role in cholesterol mobilization.

Despite its seemingly consistent favorability, HDL is relatively heterogenous in makeup. Using proton nuclear magnetic resonance (NMR) spectroscopy and vertical spin density-gradient ultracentrifugation modalities, HDL particles can be classified by density into HDL2 and HDL3 subfractions. HDL2 is the larger, more buoyant, less dense form that is rich in apoA-I, while HDL3 is the smaller, denser form that contains both apoA-I and apoA-II. ${ }^{18}$ While the apoA-I-predominant members of the HDL2 subfraction appear to be more active in reverse cholesterol transport, ${ }^{19}$ data supporting clear differences in cardiovascular risk based on HDL subfraction distribution are limited. ${ }^{18,20}$ Further investigation is needed before an understanding of HDL functionality and particle size can be applied to cardiovascular risk assessment.

\section{Relation of HDL-C and CHD in women}

Low HDL-C levels have been shown to be a risk factor for $\mathrm{CHD}$ and premature atherosclerosis independent of serum LDL-C ${ }^{21}$ and triglyceride levels. ${ }^{22}$ In women with established coronary disease, low HDL-C levels may be a better predictor of subsequent coronary events than high levels of LDL-C. ${ }^{5}$ The Nurses' Health Study estimates that a $17 \mathrm{mg} / \mathrm{dL}$ elevation in HDL-C reduces the risk of CHD development in postmenopausal women by approximately $40 \%{ }^{23}$ In general, the risk of CHD decreases by $3 \%$ for every $1 \mathrm{mg} / \mathrm{dL}$ increase in HDL-C in women, but only by $2 \%$ in men. ${ }^{24}$ Similarly, the presence of diabetes tends to confer a more negative effect on HDL-C and triglycerides (TG) in diabetic women compared to men. ${ }^{25}$

Angiographic and ultrasound evidence demonstrate that low plasma levels of HDL-C are associated with greater 
severity of CHD in females and males, as indicated by an increase in the number and extent of coronary vessel involvement. ${ }^{26}$ Furthermore, among men and women with angiographic evidence of CHD but with normal total cholesterol levels, patients with HDL-C levels $<35 \mathrm{mg} / \mathrm{dL}$ had significantly more cardiovascular events than those with higher levels. ${ }^{27}$

The Third Adult Treatment Panel of the National Cholesterol Education Panel (NCEP ATP III) broadly classified HDL-C levels less than $40 \mathrm{mg} / \mathrm{dL}$ as low and predictive of cardiovascular risk, while HDL-C levels greater than $60 \mathrm{mg} / \mathrm{dL}$ were defined as high and deemed protective. ${ }^{28}$ Reflecting gender-specific differences in serum HDL-C concentrations, however, a more inclusive risk cutpoint of $<50 \mathrm{mg} / \mathrm{dL}$ was established for identifying metabolic syndrome in women. Today, this higher HDL-C cutpoint is more commonly used when assessing cardiac risk in females, given the observed incidence of coronary disease in women with comparatively higher HDL-C levels than men. ${ }^{5,29,30}$ For these reasons, any approach to cardiovascular risk assessment should always be comprehensive.

\section{Menopause}

Prior to menopause, the risk of CHD in women is 2.5 to 4.5 times lower than that of age-matched men. ${ }^{31}$ This finding correlates to lower levels of LDL-C and higher levels of HDL-C in premenopausal women compared to males of similar age. However, within 10 years of menopause, the risk of CHD in women increases to a level similar to that in men. ${ }^{32}$ The mechanism for this precipitous rise in cardiac risk is likely multifactorial, though alterations in lipid metabolism in the face of estrogen deficiency may play a significant role. Specifically, reductions in HDL-C levels and elevations in total cholesterol, TG, fibrinogen, and lipoprotein (a) levels are observed following menopause. ${ }^{33-38}$

While age may contribute to altered lipid metabolism, menopause itself has been shown to have a stronger correlation. In a longitudinal study of 541 initially premenopausal women aged 42 to 50 years, greater changes in blood lipid levels were seen in those women who underwent menopause than in those who did not. In fact, those who maintained their premenopausal status during the study period showed no change in HDL-C levels. ${ }^{35}$ These findings support the general consensus that menopause, whether surgical or natural, is associated with a less desirable lipid profile., 2,5,16,21,22,36,39-42

In addition to bringing large absolute reductions in HDL-C levels, menopause appears to herald changes in the actual composition of HDL particles. The distribution of HDL subspecies is altered in menopause, with a reduction seen in the proportion of large, buoyant HDL2 particles, which are believed to be more active in reverse cholesterol transport. ${ }^{19}$ In contrast, smaller, more dense HDL3 subfragments rise. ${ }^{33,43}$ Additionally, ex vivo biochemical analysis of lipoproteins from pre- and post-menopausal women suggest the post-menopausal HDL particle exhibits impaired ability to limit LDL oxidation. ${ }^{44}$ While small trials such as these lack true clinical implications, they support the notion that menopause brings with it abnormalities in lipid metabolism that transcend simple changes in lipoprotein concentrations.

\section{HDL-C-raising interventions}

At the outset, lifestyle change should be recommended to all patients with low HDL-C levels. Effective lifestylebased interventions include smoking cessation, initiation of an aerobic exercise program, weight loss, moderate alcohol consumption, and adoption of a low carbohydrate or Mediterranean diet. ${ }^{28} \mathrm{~A}$ combination of these interventions may result in improved HDL-C levels, thereby reducing the need for medications. A patient's CHD risk and her starting HDL-C level will determine the need for additional pharmacologic intervention.

\section{Diet}

Diets high in omega-3 fatty acids have been shown to increase HDL-C and decrease TG levels. ${ }^{45-48}$ Foods rich in omega-3 include "oily" fish such as tuna, mackerel, sardines, and salmon. Nonaquatic food sources include walnuts, green, leafy vegetables, flaxseed oil, and certain fortified foods. The Mediterranean diet is abundant in omega-3 fatty acids and has been shown to reduce serum inflammatory markers and raise HDL-C levels, although to a minimal extent. ${ }^{49}$ Estruch et al demonstrated that a Mediterranean diet supplemented with virgin olive oil produced a significant $2.3 \mathrm{mg} / \mathrm{dL}$ increase in HDL-C at three months when compared to a Mediterranean diet with mixed nuts $(0.94 \mathrm{mg} / \mathrm{dL}$ increase $)$ and a low fat diet $(0.37 \mathrm{mg} / \mathrm{dL}$ decrease $)$. No gender differences were observed in the subgroup analysis, and beneficial effects on other cardiovascular risk factors, such as fasting plasma glucose, systolic blood pressure, and C-reactive protein, were further described. ${ }^{50}$ It should be noted, however, that trials of pharmacologic supplementation with omega-3 fatty acids have depicted only marginal benefit on HDL-C, despite substantial TG-lowering effects. ${ }^{51}$

Low-carbohydrate diets have also been shown, on average, to increase HDL-C levels by $20 \%{ }^{52}$ In a randomized, two-period, crossover study in 10 healthy normolipidemic 
women who consumed both a low fat $(<30 \%$ fat $)$ and a very low carbohydrate diet $(<10 \%$ carbohydrate), the very low carbohydrate diet increased total cholesterol, LDL-C and HDL-C by $16 \%, 15 \%$, and 33\%, respectively. ${ }^{53}$ A similar study performed by the same investigators in men demonstrated respective increases of $5 \%, 4 \%$, and $12 \%$ after a six-week very low carbohydrate diet. ${ }^{54}$ Conversely, low-fat diets typically result in a decrease of all lipoprotein levels, including a slight decrease in HDL-C levels. ${ }^{55,56}$ Controlledfeeding studies have similarly demonstrated a greater rise in HDL-C in women compared to men when diets with lower carbohydrate relative to fat are administered, illustrating differences in lipoprotein response to diet based on gender. ${ }^{57}$ Despite this, clinically-relevant cardiovascular outcomes benefits associated with low carbohydrate diets have not been described, and as such, dietary moderation may be the most prudent recommendation to patients.

\section{Alcohol intake}

A substantial body of data has demonstrated the beneficial effects of moderate alcohol intake on serum lipids, most notably an increase in HDL-C. Gaziano and colleagues examined the effects of daily moderate alcohol consumption (one to three drinks) in 340 patients ( 74 women) with previous myocardial infarction (MI), compared to an equal number of healthy patients without history of MI. ${ }^{58}$ Concentrations of HDL-C and both its major subfractions were strongly associated with alcohol consumption, and an inverse association was demonstrated between alcohol consumption and risk of MI. No such relationship was apparent for concentrations of total cholesterol, LDL-C, VLDL, or TGs. In a nested case control study examining the effects of alcohol intake in 249 women and 266 men with incident MI compared to similarly matched women and men without history of MI, frequency of drinking tended to be associated with lower risk of MI. Those with the lowest risk drank three to four days per week (with women, on average, drinking 18.2 to $20.1 \mathrm{~g}$ of alcohol per drinking day and men drinking 22.4 and 26.2 g per drinking day). Among women, multivariate analysis suggested an odds ratio $(\mathrm{OR})$ of 0.76 (95\% confidence interval [CI]: 0.59 to 0.97 ), which corresponded to a regression (r) coefficient of -0.28 per drinking day. HDL-C alone accounted for $36 \%$ of this association. In men, the OR was 0.86 (95\% CI: 0.74 to 1.0 ), with $r=-0.15$. HDL-C accounted for $53 \%$ of this association. ${ }^{59}$ These findings suggest a stronger inverse relationship of alcohol use in women over men, with HDL-C playing a large contributing role.
Moderate alcohol consumption of approximately $30 \mathrm{~g}$ per day has been shown to increase HDL-C by $4 \mathrm{mg} / \mathrm{dL}$ and apoA-I by $9 \mathrm{mg} / \mathrm{dL}$, with an overall cardiovascular risk reduction of approximately $25 \% .{ }^{60}$ Conversely, heavy alcohol consumption negates these effects through a variety of mechanisms and confers increased risk of CHD and metabolic syndrome. ${ }^{61,62}$ Progressive fatty acid accumulation, hepatic steatosis, and subsequent liver injury develop with heavy alcohol intake, mediated in part by malnutrition as well as direct cellular and mitochondrial toxicity accompanying ethanol oxidation. ${ }^{63,64}$ The exogenous and endogenous secondary hypertriglyceridemia typically seen in heavy alcohol consumption is further potentiated by increased hepatic VLDL synthesis and impaired removal of TG-containing lipoproteins from the circulation. When hepatic dysfunction is particularly severe, a paradoxical decrease in circulating HDL-C is observed, likely due in part to impaired synthesis of apoA-I and apoA-II by the dysfunctional liver. ${ }^{65,66}$

\section{Smoking}

Data suggest smoking has a similarly deleterious effect upon HDL-C concentration in women and men. A study of 2,553 women, aged 20-69 years, from 10 North American populations revealed that women who smoked 20 or more cigarettes/day had $9.4 \mathrm{mg} / \mathrm{dL}$ lower HDL-C levels when compared to nonsmokers. ${ }^{67}$ The Framingham Offspring Study revealed that active cigarette smoking was associated with an average HDL-C decrease of $4 \mathrm{mg} / \mathrm{dL}$ in men and $6 \mathrm{mg} / \mathrm{dL}$ in women. When controlled for heavy alcohol use, a significant negative association between number of cigarettes smoked and HDL-C was demonstrated in both sexes. Among those who had quit smoking for over one year, no difference in HDL-C levels was observed when compared to nonsmokers. ${ }^{68}$ Furthermore, smoking cessation may increase HDL-C levels in as little as two weeks. ${ }^{69}$

\section{Exercise}

Aerobic exercise has proven to be modestly efficacious in increasing HDL-C while decreasing total cholesterol, LDL-C, and TG in women. In a recent meta-analysis of randomized controlled trials conducted between 1955 and 2003 in which aerobic exercise was used as the primary intervention in adult women $>18$ years $(n=1022$ in exercise group, $n=633$ in control group), an HDL-C increase of $3 \%$ was noted between experimental and control groups. No statistically significant differences were noted between pre- and post-menopausal women, or those who were on pharmacotherapy affecting 
lipids and lipoprotein levels compared to participants who were not receiving treatment. A statistically significant and positive association was observed however between HDL-C and $\mathrm{V}_{\mathrm{O} 2}$ max, with greater increases in HDL-C associated with greater increases in $\mathrm{V}_{\mathrm{O} 2}$ max. Furthermore, TC, LDL-C, and TG were decreased by $2 \%, 3 \%$, and $5 \%$, respectively, with exercise. ${ }^{70}$

\section{Body habitus}

Alterations in body fat content and distribution occur naturally in both males and females with the aging process. Indices of body fat distribution and adiponectin have been demonstrated to correlate with insulin resistance in older women. The effect of weight loss on HDL-C levels, however, is unclear. Some studies in women suggest an initial decline in HDL-C with weight loss, ${ }^{71}$ while other data suggest the manner of weight loss matters more. While low-carbohydrate, high-fat diets may improve serum HDL-C, high-carbohydrate, low-fat diets tend to have fewer unwanted effects on LDL-C. ${ }^{72,73}$ Again, avoidance of diet extremes should be emphasized during weight loss.

Compared to men, women are prone to a greater frequency of HDL-C variations throughout life. Azogui and colleagues found that sex steroid hormone fluctuations during the menstrual cycle affect levels of serum lipoproteins and their constituents, particularly HDL-C. HDL-C was found to increase by $16 \%$ in the preovulatory phase, in comparison to the early follicular phase. Serum apolipoprotein A-I was elevated in the preovulatory (a 14\% increase) and mid-luteal phase (a 19\% increase) in comparison to the early follicular phase. In the mid-luteal phase, the apoA-I/HDL-C ratio was higher than in the other two phases, suggesting altered HDL composition during this phase. These findings suggest that endogenous progesterone, unlike some synthetic progestins, does not negate the beneficial effect of estrogen on serum HDL-C levels. Concentrations of other lipoproteins, including TC, TG, VLDL-C, LDL-C, and apolipoprotein-B, did not change throughout the cycle. ${ }^{74}$

Adverse alterations in the lipid profile have also been described during and after pregnancy. Additionally, pregnancy frequency, including frequency of spontaneous abortion, and age at first pregnancy have been associated with increased coronary disease risk. ${ }^{75-77}$ Analysis of data from the Coronary Artery Risk Development in Young Adults (CARDIA) study, revealed that two-year change in HDL-C was significantly different among parity groups. HDL-C levels significantly decreased in women who had their first pregnancy of at least 28 weeks duration during follow up $(-3.5 \pm 1.2 \mathrm{mg} / \mathrm{dL})$, versus an increase in HDL-C in those women parous at baseline who had no further pregnancies $(2.5 \pm 0.3 \mathrm{mg} / \mathrm{dL})$ and in nulliparous women $(2.4 \pm 0.3 \mathrm{mg} / \mathrm{dL})$. Differences in HDL-C levels remained significant after controlling for factors such as age, oral contraceptive use, changes in body mass index (BMI), waist-to-hip ratio, smoking and alcohol status, while no differences were observed in concentrations of LDL-C or TG. ${ }^{8}$ Other longitudinal ${ }^{78,79}$ and cross-sectional studies ${ }^{80,81}$ have shown similar inverse associations between multiparity and levels of HDL-C.

\section{Pharmacotherapy}

Medications have proven to be the easiest and most efficacious way to increase HDL-C levels. Combined with lifestyle-based interventions, medication effects are further amplified. In patients with established CHD, current guidelines recommend intensive lifestyle modification combined with statin-based pharmacotherapy to bring LDL-C levels to goal before HDL-C titration is attempted. There is no evidence that pharmacotherapy is necessary for primary CHD prevention in women at low to intermediate risk. ${ }^{28,82-84}$

\section{Statins}

HMG-CoA-reductase inhibitors, also known as statins, are a staple in the lipid lowering armamentarium and are used primarily to reduce LDL-C. They also have the added benefit of raising HDL-C levels, typically by $5 \%-15 \%$. Statins work by inhibiting the biosynthesis of hepatic cholesterol, upregulating the expression of hepatic LDL receptors, and stimulating hepatic production of apoA-I. ${ }^{85}$

The Air Force/Texas Coronary Atherosclerosis Prevention Study (AFCAPS/TexCaps), a primary prevention trial comparing lovastatin to placebo in 997 postmenopausal women and 5,608 men with average LDL-C levels, below average HDL-C levels and no evidence of CHD, demonstrated a 25\% reduction in LDL-C levels and a 9\% increase in HDL-C levels in postmenopausal women in the treatment group, though significant differences in lipid effects between genders were not described. ${ }^{86}$ The Greek Atorvastatin and Coronary heart disease Evaluation (GREACE) Study, a secondary prevention trial in 1,600 patients, $22 \%$ of whom were women, with known CHD described a similar 7\% increase in HDL-C levels with atorvastatin, though increases appeared proportionally greater in men $(7.8$ vs $6.1 \% ; P=0.02) .{ }^{87}$

High-dose rosuvastatin at $40 \mathrm{mg} / \mathrm{d}$ produced an even greater $14.7 \%$ increase in HDL-C in women and men while inducing regression of atheromatous plaques in a 2006 study utilizing intravascular ultrasound (IVUS). ${ }^{88}$ Statins also 
appear to provide the greatest angiographic and clinical benefit in patients with low HDL-C levels, as was evidenced in the Lipoprotein and Coronary Atherosclerosis Study. ${ }^{89}$ Changes in HDL-C with statin therapy, although modest, may contribute to additional cardiovascular risk reduction independent of LDL-C. ${ }^{90}$

\section{Fibrates}

Unlike their effects on serum TG, fibrates appear to be more modest in raising HDL-C, in the range of $10 \%-15 \% .{ }^{91,92}$ Fibric acid derivatives exert their biochemical effect by activating the peroxisome proliferator-activated receptors (PPARs) family of nuclear transcription factors. Fibrate-mediated activation of PPAR-alpha, in particular, induces synthesis of the primary HDL apolipoproteins, apoA-I and apoA-II. Additionally, fibrates upregulate lipoprotein lipase (LPL) activity and inhibit fatty acid and TG synthesis, resulting in a decrease in serum VLDL and TG concentrations. The apolipoprotein C-III (apoC-III) particle, in contrast, inhibits LPL activity, resulting in diminished catabolism of TG-containing particles such as VLDL. ${ }^{93,94}$ A null mutation in the gene encoding apoC-III has recently been discovered. Heterozygous carriers of this R19X mutation have been found to have lower serum TG, higher HDL-C, and lower coronary artery calcification and than noncarriers, ${ }^{95}$ suggesting impaired production of apoC-III may be beneficial. Fibric acid derivatives have been shown to inhibit apoC-III synthesis, thus enhancing LPL-mediated breakdown of TG-rich chylomicrons and VLDL and hepatic lipase-driven conversion of IDL to LDL. These actions indirectly increase HDL-C concentration further due to increased uptake of surface-free cholesterol and phospholipid byproducts by HDL particles. ${ }^{93,96,97}$

Published data on fibric acid derivates are less robust in women than in male subjects. In the Veterans Affairs HighDensity Lipoprotein Cholesterol Intervention Trial (VA-HIT), a secondary prevention study conducted in men, treatment with gemfibrozil (1,200 mg/day) led to a $6 \%$ increase in HDL-C along with a 4\% reduction in total cholesterol, $31 \%$ reduction in TG and no change in LDL-C relative to baseline. This conferred a $22 \%$ relative risk reduction in the composite endpoint of nonfatal myocardial infarction or CHD death. ${ }^{98}$ Of all the measured lipid changes however, the increase in HDL-C was the only on-treatment alteration to significantly correlate with reduction in CHD risk. ${ }^{99}$ The Helsinki Heart Study, another landmark trial of gemfibrozil in male subjects, described similar improvement in cardiac endpoints after five years in a primary prevention population. ${ }^{100}$ An analysis of lipoprotein particle subclasses in VA-HIT demonstrated that gemfibrozil increased LDL particle size while lowering numbers of LDL particles and increased HDL particle number and small HDL subfractions out of proportion to overall increases in HDL-C levels. ${ }^{101}$ The authors speculated that such alterations in lipoprotein makeup may be beneficial and potentially contribute to the cardiovascular risk reduction observed with gemfibrozil therapy. As noted previously, however, the clinical significance of differences in HDL subclass distribution remains unclear.

The Fenofibrate Intervention and Event Lowering in Diabetes Study (FIELD) examined 9,795 type 2 diabetics, 3,657 of whom were women, in a predominantly primary prevention setting. It depicted only small increases in HDL-C with fenofibrate therapy. At four months of treatment, fenofibrate use (200 mg/day) was associated with a $5 \%$ increase in HDL-C. The effect decreased to $2 \%$ at the end of five years of treatment, though this decrement is likely confounded by a disproportionately high drop-in rate of lipid modifying therapy, predominantly statins, in the placebo group compared to the treatment group (36\% vs $19 \%){ }^{102}$ Further published data are required to determine any gender-related differences in HDL-C modification and cardiovascular outcomes in response to fibrate therapy.

\section{Niacin}

Nicotinic acid (niacin), a water-soluble B vitamin, is the single most effective pharmacologic agent currently available for raising HDL-C. ${ }^{103}$ Therapy with niacin results in a $15 \%-35 \%$ increase in HDL-C, with the highest increases reported with doses of $1-2 \mathrm{~g}$ daily. ${ }^{104}$ Niacin additionally provides significant decreases in LDL-C and TG levels, ${ }^{105}$ and up to a $39 \%$ reduction in lipoprotein(a) levels. ${ }^{106,107}$ Niacin also appears to affect lipoprotein subclass distribution favorably. Observed is a decrease in small, dense atherogenic LDL particles and an increase in large, buoyant HDL particles comprising the HDL2 subfraction, without a net effect on small HDL particles. ${ }^{12}$ A meta-analysis of trials of extendedrelease niacin in men and women demonstrated similar effects on HDL-C by gender, and statistically significant more favorable effects on LDL-C and TG in women compared to men. ${ }^{108}$ Major limitations to widespread use of niacin, however, include the high prevalence of intolerance due to flushing and smaller adverse effects on glucose metabolism, though extended-release formulations appear to be more tolerable from with regard to flushing. ${ }^{104,106,107}$

Combination therapy of niacin with other agents has been shown to provide greater increases in HDL-C in trials involving women and men. When statins and fibrates are 
used together, a $22 \%$ increase in HDL-C has been described. Similarly, the combination of statins and niacin may produce a 27\% improvement in HDL-C. ${ }^{109,110}$ Such combined drug regimens have been shown to induce regression of atherosclerotic coronary plaques in women. ${ }^{109-111}$

\section{Estrogen}

Estrogen replacement therapy has been shown to have a favorable effect on lipid and lipoprotein levels. HDL-C increases of up to $15 \%$ and an LDL-C decrease of $15 \%$ can be expected with use of oral estrogen. ${ }^{12,113}$ However, despite this apparently beneficial effect on serum lipids, estrogen replacement therapy has demonstrated no benefit in reducing coronary outcomes in postmenopausal women. The Heart and Estrogen/Progestin Replacement Study (HERS) showed a statistically significant $52 \%$ increase in the risk of cardiac death or nonfatal MI during the first year of follow-up in postmenopausal women treated with combined estrogen plus progestin. A similar early increase in risk of pulmonary embolism and coronary events was observed during the first 3 years of the Women's Health Initiative (WHI). ${ }^{114,115}$ Although these findings may be slightly offset by the inclusion of older women who lacked menopausal symptoms, current recommendations do not support the use of estrogen replacement therapy to reduce cardiovascular risk in postmenopausal women.

\section{Emerging therapies}

In light of the recent discovery of the R19X null mutation for the apoC-III gene and its apparent cardioprotective effects, treatments targeted specifically toward downregulation of apoC-III may soon be examined. Promising new therapies to raise HDL-C that are already being investigated include CETP inhibitors, exogenous HDL mimetics, and ABCA1 upregulators. Given the emerging nature of these therapies, however, little gender-specific data currently exist.

Among the CETP inhibitors currently under investigation are JTT-705 and anacetrapib. In small pre-marketing trials using healthy men and women with mild dyslipidemia, JTT-705 has been shown to increase HDL-C by 34\% and decrease LDL-C by $7 \%$. The compound demonstrated no significant toxicity and was effective at increasing both HDL2 and HDL 3 subfractions. ${ }^{116}$ Torcetrapib, the first CETP inhibitor studied, demonstrated dramatic increases in HDL-C when combined with atorvastatin compared to atorvastatin alone in a large-scale clinical trial involving 15,067 male and female subjects deemed to be at high cardiac risk. ${ }^{117}$ The addition of torcetrapib to atorvastatin conferred a $72.1 \%$ increase in HDL-C and 24.9\% decrease in LDL-C following 12 months of therapy. The trial was ultimately terminated, however, due to increased morbidity and mortality in the experimental arm. In particular, the addition of torcetrapib was associated with increased risk for cardiovascular events (hazard ratio, 1.25; 95\% CI: 1.09-1.44; $P=0.001$ ), as well as death from any cause (hazard ratio, $1.58 ; 95 \%$ CI: $1.14-2.19 ; P=0.006)$. There were more deaths from cardiovascular causes (49 vs 35) as well as noncardiovascular causes (40 vs 20) in the experimental arm. Also seen in the torcetrapib group were increases in blood pressure $(5.4 \mathrm{mmHg}$ systolic and $2.0 \mathrm{mmHg}$ diastolic), decreases in potassium concentration, and increases in sodium and bicarbonate levels. Consequently, mineralocorticoid excess has been proposed as a potential mechanism of torcetrapib-induced cardiovascular harm, and this theory has been supported by the post hoc observation of increased serum aldosterone concentrations in torcetrapib-treated patients. An alternate suggested explanation for the observed adverse cardiovascular outcomes in the torcetrapib group involves the supposition that CETP inhibition may actually produce HDL particles that are less functional or potentially harmful. ${ }^{117}$ Similar deleterious effects on outcomes or blood pressure have not yet been reported in smaller-scale trials of anacetrapib, another CETP inhibitor under investigation, which has shown up to a $40 \%$ reduction in LDL-C and 139\% increase in HDL-C compared to placebo, and incremental effects on LDL when combined with atorvastatin. ${ }^{118}$ Further study is required to determine whether CETP inhibition is an effective and safe strategy to halt atherosclerosis and reduce cardiovascular events.

ApoA-I Milano, a naturally occurring variant of apo A-I, is found in individuals with very low levels of HDL-C but no overt signs of atherosclerosis. ${ }^{119}$ Intravenous administration of a recombinant form of apoA-I Milano was recently examined in patients with recent acute coronary syndrome events. As assessed by intravascular ultrasound, significant coronary atheroma regression was seen in patients receiving intravenous infusions of recombinant apoA-I Milano, while those receiving placebo experienced plaque progression. ${ }^{120}$ In animal studies, the recombinant compound facilitates the formation of large HDL particles, which appear to be more active in reverse cholesterol transport. ${ }^{121}$ Gene therapy with apoA-I Milano is currently being investigated in the murine model and may represent a promising new approach to reducing atherosclerosis. ${ }^{122}$

Another trial of infusion therapy involved CSL-111, a reconstituted HDL (rHDL) constructed from human apoA-I combined with soybean-derived phosphatidylcholine. 
The Effect of rHDL on Atherosclerosis-Safety and Efficacy (ERASE) study found that four weekly infusions of reconstituted HDL failed to significantly change coronary atheroma volume as assessed by IVUS compared to placebo, though investigators did report statistically significant improvements in the plaque characterization index on IVUS and coronary score on quantitative coronary angiography. Additionally, patients randomized to receive a higher dose of CSL-111 experienced elevations in aminotransferase levels, prompting premature discontinuation in the high dose group. ${ }^{123}$

Patients with Tangier disease and familial HDL deficiency have mutations in the $\mathrm{ABCA} 1$, resulting in severely diminished concentrations of HDL-C. Thus, upregulation of the ABCA1 transporter may represent a new therapeutic model for increasing HDL-C levels. ABC transporters are expressed in macrophages and are thought to mediate cholesterol efflux from macrophage foam cells into the major HDL fractions. ${ }^{124}$ This might explain the inverse relationship between HDL-C levels and atherosclerosis risk. Drugs that induce $\mathrm{ABCA} 1$ in mice increase clearance of cholesterol from tissues and inhibit intestinal absorption of dietary cholesterol. ${ }^{125}$ More translational research on the effects of ABCA1 in humans is needed to delineate the benefits that ABCA1-targeted compounds may provide.

\section{Conclusion}

Baseline HDL-C levels are inextricably linked to cardiovascular outcomes in women and men. Many new and effective strategies exist to raise HDL-C in women. Among drug therapies, niacin continues to be the most effective, especially when combined with fibrate or statin therapy. Currently, no role exists for the use of estrogen replacement therapy to raise HDL-C or to reduce cardiovascular risk in postmenopausal women. Lifestyle alterations that include dietary changes, smoking cessation and aerobic exercise must be employed concomitantly with pharmacotherapy to achieve the best clinical results. New modalities currently being investigated to further increase HDL-C levels include CETP inhibitors, exogenous HDL mimetics, and ABCA1 upregulators.

\section{Disclosures}

The authors report no conflicts of interest in this work.

\section{References}

1. American Heart Association. Facts about Women and Cardiovascular Diseases. 2008. Available from: http://www.americanheart.org/ presenter.jhtml?identifier=2876. Accessed August 14, 2008.

2. Kuvin JT, Alsheikh-Ali AA, Karas RH. High-density lipoprotein cholesterol-raising strategies. J Cardiovasc Pharmacol. 2006;47(2): 196-204.
3. Goldbourt U, Medalie JH. High density lipoprotein cholesterol and incidence of coronary heart disease - the Israeli Ischemic Heart Disease Study. Am J Epidemiol. 1979;109(3):296-308.

4. Castelli WP. Cardiovascular disease in women. Am J Obstet Gynecol. 1988;158(6 Pt 2):1553-60, 1566-1557.

5. Bass KM, Newschaffer CJ, Klag MJ, Bush TL. Plasma lipoprotein levels as predictors of cardiovascular death in women. Arch Intern Med. 1993;153(19):2209-2216.

6. Wilson PW, Abbott RD, Castelli WP. High density lipoprotein cholesterol and mortality. The Framingham Heart Study. Arteriosclerosis. 1988;8(6):737-741.

7. von Eckardstein A, Nofer JR, Assmann G. High density lipoproteins and arteriosclerosis. Role of cholesterol efflux and reverse cholesterol transport. Arterioscler Thromb Vasc Biol. 2001;21(1):13-27.

8. Lewis CE, Funkhouser E, Raczynski JM, Sidney S, Bild DE, Howard BV. Adverse effect of pregnancy on high density lipoprotein (HDL) cholesterol in young adult women. The CARDIA Study. Coronary Artery Risk Development in Young Adults. Am J Epidemiol. 1996;144(3):247-254.

9. Glomset JA, Janssen ET, Kennedy R, Dobbins J. Role of plasma lecithin:cholesterol acyltransferase in the metabolism of high density lipoproteins. J Lipid Res. 1966;7(5):638-648.

10. Acton S, Rigotti A, Landschulz KT, Xu S, Hobbs HH, Krieger M. Identification of scavenger receptor SR-BI as a high density lipoprotein receptor. Science. 1996;271(5248):518-520.

11. Brewer HB Jr. Increasing HDL Cholesterol Levels. $N$ Engl J Med. 2004;350(15):1491-1494

12. Morgan JM, Capuzzi DM, Baksh RI, et al. Effects of extendedrelease niacin on lipoprotein subclass distribution. Am J Cardiol. 2003;91(12):1432-1436.

13. Cockerill GW, Rye KA, Gamble JR, Vadas MA, Barter PJ. High-density lipoproteins inhibit cytokine-induced expression of endothelial cell adhesion molecules. Arterioscler Thromb Vasc Biol. 1995; 15(11):1987-1994.

14. Cockerill GW, Saklatvala J, Ridley SH, et al. High-density lipoproteins differentially modulate cytokine-induced expression of E-selectin and cyclooxygenase-2. Arterioscler Thromb Vasc Biol. 1999;19(4):910-917.

15. Xia P, Vadas MA, Rye KA, Barter PJ, Gamble JR. High density lipoproteins (HDL) interrupt the sphingosine kinase signaling pathway. A possible mechanism for protection against atherosclerosis by HDL. J Biol Chem. 1999;274(46):33143-33147.

16. Yuhanna IS, Zhu Y, Cox BE, et al. High-density lipoprotein binding to scavenger receptor-BI activates endothelial nitric oxide synthase. Nat Med. 2001;7(7):853-857.

17. Kuvin JT, Ramet ME, Patel AR, Pandian NG, Mendelsohn ME, Karas RH. A novel mechanism for the beneficial vascular effects of high-density lipoprotein cholesterol: enhanced vasorelaxation and increased endothelial nitric oxide synthase expression. Am Heart J. 2002; 144(1):165-172.

18. Freedman DS, Otvos JD, Jeyarajah EJ, Barboriak JJ, Anderson AJ, Walker JA. Relation of lipoprotein subclasses as measured by proton nuclear magnetic resonance spectroscopy to coronary artery disease. Arterioscler Thromb Vasc Biol. 1998;18(7):1046-1053.

19. Huang Y, von Eckardstein A, Wu S, Assmann G. Cholesterol efflux, cholesterol esterification, and cholesteryl ester transfer by LpA-I and LpA-I/A-II in native plasma. Arterioscler Thromb Vasc Biol. 1995;15(9):1412-1418.

20. Salonen JT, Salonen R, Seppanen K, Rauramaa R, Tuomilehto J. HDL, HDL2, and HDL3 subfractions, and the risk of acute myocardial infarction. A prospective population study in eastern Finnish men. Circulation. 1991;84(1):129-139.

21. Castelli WP, Garrison RJ, Wilson PW, Abbott RD, Kalousdian S, Kannel WB. Incidence of coronary heart disease and lipoprotein cholesterol levels. The Framingham Study. JAMA. 1986;256(20):2835-38.

22. Castelli WP. Cholesterol and lipids in the risk of coronary artery disease - the Framingham Heart Study. Can J Cardiol. 1988; 4(Suppl A):5A-10A. 
23. Shai I, Rimm EB, Hankinson SE, et al. Multivariate assessment of lipid parameters as predictors of coronary heart disease among postmenopausal women: potential implications for clinical guidelines. Circulation. 2004;110(18):2824-2830.

24. Gordon DJ, Probstfield JL, Garrison RJ, et al. High-density lipoprotein cholesterol and cardiovascular disease. Four prospective American studies. Circulation. 1989;79(1):8-15.

25. Walden CE, Knopp RH, Wahl PW, Beach KW, Strandness E, Jr. Sex differences in the effect of diabetes mellitus on lipoprotein triglyceride and cholesterol concentrations. N Engl J Med. 1984;311(15):953-959.

26. Pearson TA, Bulkley BH, Achuff SC, Kwiterovich PO, Gordis L. The association of low levels of HDL cholesterol and arteriographically defined coronary artery disease. Am J Epidemiol. 1979;109(3):285-295.

27. Miller M, Seidler A, Kwiterovich PO, Pearson TA. Long-term predictors of subsequent cardiovascular events with coronary artery disease and 'desirable' levels of plasma total cholesterol. Circulation. 1992;86(4):1165-1170.

28. Executive Summary of The Third Report of The National Cholesterol Education Program (NCEP) Expert Panel on Detection, Evaluation, And Treatment of High Blood Cholesterol In Adults (Adult Treatment Panel III). JAMA. 2001;285(19):2486-2497.

29. Gordon T, Castelli WP, Hjortland MC, Kannel WB, Dawber TR. High density lipoprotein as a protective factor against coronary heart disease. The Framingham Study. Am J Med. 1977;62(5):707-714.

30. Corti MC, Guralnik JM, Salive ME, et al. HDL cholesterol predicts coronary heart disease mortality in older persons. JAMA. 1995;274(7):539-544.

31. Kalin MF, Zumoff B. Sex hormones and coronary disease: a review of the clinical studies. Steroids. 1990;55(8):330-352

32. Kafonek SD. Postmenopausal hormone replacement therapy and cardiovascular risk reduction. A review. Drugs. 1994;47(Suppl 2):16-24.

33. Stevenson JC, Crook D, Godsland IF. Influence of age and menopause on serum lipids and lipoproteins in healthy women. Atherosclerosis. 1993;98(1):83-890.

34. Razay $\mathrm{G}$, Heaton $\mathrm{KW}$, Bolton $\mathrm{CH}$. Coronary heart disease risk factors in relation to the menopause. Q J Med. 1992;85(307-308):889-896.

35. Matthews KA, Meilahn E, Kuller LH, Kelsey SF, Caggiula AW, Wing RR. Menopause and risk factors for coronary heart disease. N Engl J Med. 1989;321(10):641-646.

36. Jensen J, Nilas L, Christiansen C. Influence of menopause on serum lipids and lipoproteins. Maturitas. 1990;12(4):321-331.

37. Jenner JL, Ordovas JM, Lamon-Fava S, et al. Effects of age, sex, and menopausal status on plasma lipoprotein(a) levels. The Framingham Offspring Study. Circulation. 1993;87(4):1135-1141.

38. Folsom AR. Epidemiology of fibrinogen. Eur Heart J. 1995; 16(Suppl A):21-23; discussion 23-24.

39. Urabe M, Yamamoto T, Kashiwagi T, et al. Effect of estrogen replacement therapy on hepatic triglyceride lipase, lipoprotein lipase and lipids including apolipoprotein E in climacteric and elderly women Endocr J. 1996;43(6):737-742.

40. Poehlman ET, Toth MJ, Ades PA, Rosen CJ. Menopause-associated changes in plasma lipids, insulin-like growth factor I and blood pressure: a longitudinal study. Eur J Clin Invest. 1997;27(4):322-326.

41. Pasquali R, Casimirri F, Pascal G, et al. Influence of menopause on blood cholesterol levels in women: the role of body composition, fat distribution and hormonal milieu. Virgilio Menopause Health Group. J Intern Med. 1997;241(3):195-203.

42. Lip GY, Blann AD, Jones AF, Beevers DG. Effects of hormonereplacement therapy on hemostatic factors, lipid factors, and endothelial function in women undergoing surgical menopause: implications for prevention of atherosclerosis. Am Heart J. 1997;134(4):764-771.

43. Li Z, McNamara JR, Fruchart JC, et al. Effects of gender and menopausal status on plasma lipoprotein subspecies and particle sizes. J Lipid Res. 1996;37(9):1886-1896.

44. Zago V, Sanguinetti S, Brites F, et al. Impaired high density lipoprotein antioxidant activity in healthy postmenopausal women. Atherosclerosis. 2004;177(1):203-210.
45. Svensson M, Christensen JH, Solling J, Schmidt EB. The effect of n-3 fatty acids on plasma lipids and lipoproteins and blood pressure in patients with CRF. Am J Kidney Dis. 2004;44(1):77-83.

46. Okuda N, Ueshima H, Okayama A, et al. Relation of long chain n-3 polyunsaturated fatty acid intake to serum high density lipoprotein cholesterol among Japanese men in Japan and Japanese-American men in Hawaii: the INTERLIPID study. Atherosclerosis. 2005;178(2):371-379.

47. Esposito K, Marfella R, Ciotola M, et al. Effect of a mediterraneanstyle diet on endothelial dysfunction and markers of vascular inflammation in the metabolic syndrome: a randomized trial. JAMA. 2004;292(12):1440-1446.

48. Dallongeville J, Yarnell J, Ducimetiere P, et al. Fish consumption is associated with lower heart rates. Circulation. 2003;108(7):820-825.

49. Chrysohoou C, Panagiotakos DB, Pitsavos C, Das UN, Stefanadis C. Adherence to the Mediterranean diet attenuates inflammation and coagulation process in healthy adults: The ATTICA Study. J Am Coll Cardiol. 2004;44(1):152-158.

50. Estruch R, Martinez-Gonzalez MA, Corella D, et al. Effects of a Mediterranean-style diet on cardiovascular risk factors: a randomized trial. Ann Intern Med. 2006;145(1):1-11.

51. Balk EM, Lichtenstein AH, Chung M, Kupelnick B, Chew P, Lau J. Effects of omega-3 fatty acids on serum markers of cardiovascular disease risk: a systematic review. Atherosclerosis. 2006;189(1):19-30.

52. Foster GD, Wyatt HR, Hill JO, et al. A randomized trial of a lowcarbohydrate diet for obesity. N Engl J Med. 2003;348(21):2082-2090.

53. Volek JS, Sharman MJ, Gomez AL, Scheett TP, Kraemer WJ. An isoenergetic very low carbohydrate diet improves serum HDL cholesterol and triacylglycerol concentrations, the total cholesterol to HDL cholesterol ratio and postprandial pipemic responses compared with a low fat diet in normal weight, normolipidemic women. J Nutr. 2003;133(9):2756-2761.

54. Sharman MJ, Kraemer WJ, Love DM, et al. A ketogenic diet favorably affects serum biomarkers for cardiovascular disease in normal-weight men. J Nutr. 2002;132(7):1879-1885.

55. Yu-Poth S, Zhao G, Etherton T, Naglak M, Jonnalagadda S, KrisEtherton PM. Effects of the National Cholesterol Education Program's Step I and Step II dietary intervention programs on cardiovascular disease risk factors: a meta-analysis. Am J Clin Nutr. 1999;69(4):632-646.

56. Schaefer EJ, Lichtenstein AH, Lamon-Fava S, et al. Efficacy of a National Cholesterol Education Program Step 2 diet in normolipidemic and hypercholesterolemic middle-aged and elderly men and women. Arterioscler Thromb Vasc Biol. 1995;15(8):1079-1085.

57. Knopp RH, Paramsothy P, Retzlaff BM, et al. Gender differences in lipoprotein metabolism and dietary response: basis in hormonal differences and implications for cardiovascular disease. Curr Atheroscler Rep. 2005;7(6):472-479.

58. Gaziano JM, Buring JE, Breslow JL, et al. Moderate alcohol intake, increased levels of high-density lipoprotein and its subfractions, and decreased risk of myocardial infarction. $N \mathrm{Engl} \mathrm{J} \mathrm{Med}$. 1993;329(25):1829-1834.

59. Mukamal KJ, Jensen MK, Gronbaek M, et al.Drinking frequency, mediating biomarkers, and risk of myocardial infarction in women and men. Circulation. 2005;112(10):1406-1413.

60. Rimm EB, Williams P, Fosher K, Criqui M, Stampfer MJ. Moderate alcohol intake and lower risk of coronary heart disease: meta-analysis of effects on lipids and haemostatic factors. BMJ. 1999;319(7224): 1523-1528.

61. Godsland IF, Leyva F, Walton C, Worthington M, Stevenson JC. Associations of smoking, alcohol and physical activity with risk factors for coronary heart disease and diabetes in the first follow-up cohort of the Heart Disease and Diabetes Risk Indicators in a Screened Cohort study (HDDRISC-1). J Intern Med. 1998;244(1):33-41.

62. Fan AZ, Russell M, Dorn J, et al. Lifetime alcohol drinking pattern is related to the prevalence of metabolic syndrome. The Western New York Health Study (WNYHS). Eur J Epidemiol. 2006;21(2):129-138.

63. Steinberg D, Pearson TA, Kuller LH. Alcohol and atherosclerosis. Ann Intern Med. 1991;114(11):967-976. 
64. Lieber CS. Alcoholic fatty liver: its pathogenesis and mechanism of progression to inflammation and fibrosis. Alcohol. 2004;34(1):9-19.

65. Hopkins PN, Williams RR. A simplified approach to lipoprotein kinetics and factors affecting serum cholesterol and triglyceride concentrations. Am J Clin Nutr. 1981;34(11):2560-2590.

66. Devenyi P, Robinson GM, Roncari DA. Alcohol and high-density lipoproteins. Can Med Assoc J. 1980;123(10):981-984.

67. Criqui MH, Wallace RB, Heiss G, Mishkel M, Schonfeld G, Jones GT. Cigarette smoking and plasma high-density lipoprotein cholesterol. The Lipid Research Clinics Program Prevalence Study. Circulation. 1980;62(4 Pt 2):IV70-IV76.

68. Garrison RJ, Kannel WB, Feinleib M, Castelli WP, McNamara PM, Padgett SJ. Cigarette smoking and HDL cholesterol: the Framingham offspring study. Atherosclerosis. 1978;30(1):17-25.

69. Moffatt RJ. Effects of cessation of smoking on serum lipids and high density lipoprotein-cholesterol. Atherosclerosis. 1988;74(1-2):85-89.

70. Kelley GA, Kelley KS, Tran ZV. Aerobic exercise and lipids and lipoproteins in women: a meta-analysis of randomized controlled trials. J Womens Health (Larchmt). 2004;13(10):1148-1164.

71. Mazzali G, Di Francesco V, Zoico E, et al. Interrelations between fat distribution, muscle lipid content, adipocytokines, and insulin resistance: effect of moderate weight loss in older women. Am J Clin Nutr. 2006;84(5):1193-1199.

72. Tay J, Brinkworth GD, Noakes M, Keogh J, Clifton PM. Metabolic effects of weight loss on a very-low-carbohydrate diet compared with an isocaloric high-carbohydrate diet in abdominally obese subjects. $J \mathrm{Am}$ Coll Cardiol. 2008;51(1):59-67.

73. Miller M, Beach V, Sorkin JD, et al. Comparative effects of three popular diets on lipids, endothelial function, and C-reactive protein during weight maintenance. J Am Diet Assoc. 2009;109(4):713-717.

74. Azogui G, Ben-Shlomo I, Zohar S, Kook A, Presser S, Aviram M. High density lipoprotein concentration is increased during the ovulatory phase of the menstrual cycle in healthy young women. Gynecol Endocrinol. 1992;6(4):253-257.

75. Winkelstein W Jr, Stenchever MA, Lilienfeld AM. Occurrence of pregnancy, abortion, and artificial menopause among women with coronary artery disease: a preliminary study. J Chronic Dis. 1958;7(4):273-286.

76. Bengtsson C, Rybo G, Westerberg H. Number of pregnancies, use of oral contraceptives and menopausal age in women with ischemic heart disease, compared to a population sample of women. Acta Med Scand. 1973;549:75-81.

77. Beard CM, Fuster V, Annegers JF. Reproductive history in women with coronary heart disease. A case-control study. Am J Epidemiol. 1984;120(1):108-114.

78. Hubert HB, Eaker ED, Garrison RJ, Castelli WP. Life-style correlates of risk factor change in young adults: an eight-year study of coronary heart disease risk factors in the Framingham offspring. Am J Epidemiol. 1987;125(5):812-831.

79. Haertel U, Heiss G, Filipiak B, Doering A. Cross-sectional and longitudinal associations between high density lipoprotein cholesterol and women's employment. Am J Epidemiol. 1992;135(1):68-78.

80. Kritz-Silverstein D, Barrett-Connor E, Wingard DL. The relationship between multiparity and lipoprotein levels in older women. $J$ Clin Epidemiol. 1992;45(7):761-767.

81. Flegal KM, Ness RB, Kramer RA. Parity and high density lipoprotein (HDL) cholesterol levels in white women from the Second National Health and Nutrition Examination Survey (NHANES II). Am J Epidemiol. 1990;132:766.

82. Mosca L, Banka CL, Benjamin EJ, et al. Evidence-based guidelines for cardiovascular disease prevention in women: 2007 update. Circulation. 2007;115(11):1481-1501

83. Mosca L, Appel LJ, Benjamin EJ, et al. Evidence-based guidelines for cardiovascular disease prevention in women. Circulation. 2004;109(5): 672-693.

84. International Atherosclerosis Society. Harmonized clinical guidelines on prevention of atherosclerotic vascular disease [online]. Available from: http://www.athero.org. Accessed on August 10, 2009.
85. Schaefer JR, Schweer H, Ikewaki K, et al. Metabolic basis of high density lipoproteins and apolipoprotein A-I increase by HMG-CoA reductase inhibition in healthy subjects and a patient with coronary artery disease. Atherosclerosis. 1999;144(1):177-184.

86. Downs JR, Clearfield M, Weis S, et al. Primary prevention of acute coronary events with lovastatin in men and women with average cholesterol levels: results of AFCAPS/TexCAPS. Air Force/Texas Coronary Atherosclerosis Prevention Study. JAMA. 1998;279(20):1615-1622.

87. Athyros VG, Mikhailidis DP, Papageorgiou AA, et al. Effect of atorvastatin on high density lipoprotein cholesterol and its relationship with coronary events: a subgroup analysis of the GREek Atorvastatin and Coronary-heart-disease Evaluation (GREACE) Study. Curr Med Res Opin. 2004;20(5):627-637.

88. Nissen SE, Nicholls SJ, Sipahi I, et al. Effect of very high-intensity statin therapy on regression of coronary atherosclerosis: the ASTEROID trial. JAMA. 2006;295(13):1556-1565.

89. Ballantyne CM, Herd JA, Ferlic LL, et al. Influence of low HDL on progression of coronary artery disease and response to fluvastatin therapy. Circulation. 1999; 99(6):736-743.

90. Pedersen TR, Olsson AG, Faergeman O, et al. Lipoprotein changes and reduction in the incidence of major coronary heart disease events in the Scandinavian Simvastatin Survival Study (4S). Circulation. 1998;97(15):1453-1460.

91. Birjmohun RS, Hutten BA, Kastelein JJ, Stroes ES. Efficacy and safety of high-density lipoprotein cholesterol-increasing compounds: a meta-analysis of randomized controlled trials. J Am Coll Cardiol. 2005;45(2):185-197.

92. Belalcazar LM, Ballantyne CM. Defining specific goals of therapy in treating dyslipidemia in the patient with low high-density lipoprotein cholesterol. Prog Cardiovasc Dis. 1998;41(2):151-174.

93. Staels B, Dallongeville J, Auwerx J, Schoonjans K, Leitersdorf E, Fruchart JC. Mechanism of action of fibrates on lipid and lipoprotein metabolism. Circulation. 1998;98(19):2088-2093.

94. Saku K, Gartside PS, Hynd BA, Kashyap ML. Mechanism of action of gemfibrozil on lipoprotein metabolism. J Clin Invest. 1985;75(5): $1702-1712$.

95. Pollin TI, Damcott CM, Shen H, et al. A null mutation in human APOC3 confers a favorable plasma lipid profile and apparent cardioprotection. Science. 2008;322(5908):1702-1705.

96. Fruchart JC. Peroxisome proliferator-activated receptor-alpha activation and high-density lipoprotein metabolism. Am J Cardiol. $2001 ; 88(12 \mathrm{~A}): 24 \mathrm{~N}-29 \mathrm{~N}$.

97. Corella D, Guillen M, Saiz C, et al. Associations of LPL and APOC3 gene polymorphisms on plasma lipids in a Mediterranean population: interaction with tobacco smoking and the APOE locus. J Lipid Res. 2002;43(3):416-427.

98. Rubins HB, Robins SJ, Collins D, et al. Gemfibrozil for the secondary prevention of coronary heart disease in men with low levels of high-density lipoprotein cholesterol. Veterans Affairs High-Density Lipoprotein Cholesterol Intervention Trial Study Group. $N$ Engl $J$ Med. 1999;341(6):410-418.

99. Robins SJ, Collins D, Wittes JT, et al. Relation of gemfibrozil treatment and lipid levels with major coronary events: VA-HIT: a randomized controlled trial. JAMA. 2001;285(12):1585-1591.

100. Frick MH, Elo O, Haapa K, et al. Helsinki Heart Study: primary-prevention trial with gemfibrozil in middle-aged men with dyslipidemia. Safety of treatment, changes in risk factors, and incidence of coronary heart disease. N Engl J Med. 1987;317(20):1237-1245.

101. Otvos JD, Collins D, Freedman DS, et al. Low-density lipoprotein and high-density lipoprotein particle subclasses predict coronary events and are favorably changed by gemfibrozil therapy in the Veterans Affairs High-Density Lipoprotein Intervention Trial. Circulation. 2006;113(12):1556-1563.

102. Keech A, Simes RJ, Barter P, et al. Effects of long-term fenofibrate therapy on cardiovascular events in 9795 people with type 2 diabetes mellitus (the FIELD study): randomised controlled trial. Lancet. 2005;366(9500):1849-1861. 
103. Alderman JD, Pasternak RC, Sacks FM, Smith HS, Monrad ES, Grossman W. Effect of a modified, well-tolerated niacin regimen on serum total cholesterol, high density lipoprotein cholesterol and the cholesterol to high density lipoprotein ratio. Am J Cardiol. 1989;64(12):725-729.

104. Goldberg A, Alagona P, Jr., Capuzzi DM, et al. Multiple-dose efficacy and safety of an extended-release form of niacin in the management of hyperlipidemia. Am J Cardiol. 2000;85(9):1100-1105.

105. Lavie CJ, Mailander L, Milani RV. Marked benefit with sustainedrelease niacin therapy in patients with "isolated" very low levels of high-density lipoprotein cholesterol and coronary artery disease. Am J Cardiol. 1992;69(12):1083-1085.

106. Morgan JM, Capuzzi DM, Guyton JR, et al. Treatment Effect of Niaspan, a Controlled-release Niacin, in Patients With Hypercholesterolemia: A Placebo-controlled Trial. J Cardiovasc Pharmacol Ther 1996;1(3):195-202.

107. Knopp RH, Alagona P, Davidson M, et al. Equivalent efficacy of a timerelease form of niacin (Niaspan) given once-a-night versus plain niacin in the management of hyperlipidemia. Metabolism. 1998;47(9):1097-1104.

108. Goldberg AC. A meta-analysis of randomized controlled studies on the effects of extended-release niacin in women. Am J Cardiol. 2004;94(1):121-124.

109. Taher TH, Dzavik V, Reteff EM, Pearson GJ, Woloschuk BL, Francis GA. Tolerability of statin-fibrate and statin-niacin combination therapy in dyslipidemic patients at high risk for cardiovascular events. Am J Cardiol. 2002;89(4):390-394.

110. Brown BG, Zhao XQ, Chait A, et al. Simvastatin and niacin, antioxidant vitamins, or the combination for the prevention of coronary disease. N Engl J Med. 2001;345(22):1583-1592.

111. Kane JP, Malloy MJ, Ports TA, Phillips NR, Diehl JC, Havel RJ. Regression of coronary atherosclerosis during treatment of familial hypercholesterolemia with combined drug regimens. JAMA. 1990;264(23):3007-3012.

112. Walsh BW, Schiff I, Rosner B, Greenberg L, Ravnikar V, Sacks FM. Effects of postmenopausal estrogen replacement on the concentrations and metabolism of plasma lipoproteins. N Engl J Med. 1991;325(17): 1196-1204.

113. Binder EF, Williams DB, Schechtman KB, Jeffe DB, Kohrt WM. Effects of hormone replacement therapy on serum lipids in elderly women. a randomized, placebo-controlled trial. Ann Intern Med 2001;134(9 Pt 1):754-760.

114. Rossouw JE, Anderson GL, Prentice RL, et al. Risks and benefits of estrogen plus progestin in healthy postmenopausal women: principal results From the Women's Health Initiative randomized controlled trial. JAMA. 2002;288(3):321-333.
115. Grady D, Herrington D, Bittner V, et al. Cardiovascular disease outcomes during 6.8 years of hormone therapy: Heart and Estrogen/progestin Replacement Study follow-up (HERS II). JAMA. 2002;288(1):49-57.

116. de Grooth GJ, Kuivenhoven JA, Stalenhoef AF, et al. Efficacy and safety of a novel cholesteryl ester transfer protein inhibitor, JTT-705, in humans: a randomized phase II dose-response study. Circulation. 2002;105(18):2159_2165.

117. Barter PJ, Caulfield M, Eriksson M, et al. Effects of torcetrapib in patients at high risk for coronary events. $N$ Engl J Med. 2007;357(21):2109-222.

118. Bloomfield D, Carlson GL, Sapre A, et al. Efficacy and safety of the cholesteryl ester transfer protein inhibitor anacetrapib as monotherapy and coadministered with atorvastatin in dyslipidemic patients. Am Heart J. 2009;157(2):352-360, e352.

119. Franceschini G, Sirtori CR, Capurso A, 2nd, Weisgraber KH, Mahley RW. A-IMilano apoprotein. Decreased high density lipoprotein cholesterol levels with significant lipoprotein modifications and without clinical atherosclerosis in an Italian family. $J$ Clin Invest. 1980;66(5):892-900.

120. Nissen SE, Tsunoda T, Tuzcu EM, et al. Effect of recombinant ApoA-I Milano on coronary atherosclerosis in patients with acute coronary syndromes: a randomized controlled trial. JAMA. 2003;290(17): 2292-2300.

121. Shah PK, Yano J, Reyes O, et al. High-dose recombinant apolipoprotein A-I(milano) mobilizes tissue cholesterol and rapidly reduces plaque lipid and macrophage content in apolipoprotein e-deficient mice. Potential implications for acute plaque stabilization. Circulation. 2001;103(25):3047-3050.

122. Wang L, Sharifi BG, Pan T, Song L, Yukht A, Shah PK. Bone marrow transplantation shows superior atheroprotective effects of gene therapy with apolipoprotein A-I Milano compared with wild-type apolipoprotein A-I in hyperlipidemic mice. $\mathrm{J}$ Am Coll Cardiol. 2006;48(7):1459-1468.

123. Tardif JC, Gregoire J, L'Allier PL, et al. Effects of reconstituted high-density lipoprotein infusions on coronary atherosclerosis: a randomized controlled trial. JAMA. 2007;297(15):1675-1682.

124. Wang N, Lan D, Chen W, Matsuura F, Tall AR. ATP-binding cassette transporters G1 and G4 mediate cellular cholesterol efflux to high-density lipoproteins. Proc Natl Acad Sci U S A. 2004;101(26):9774-9779.

125. Oram JF, Lawn RM. ABCA1. The gatekeeper for eliminating excess tissue cholesterol. J Lipid Res. 2001;42(8):1173-1179.
International Journal of Women's Health

\section{Publish your work in this journal}

The International Journal of Women's Health is an international, peerreviewed open-access journal publishing original research, reports, reviews and commentaries on all aspects of women's healthcare including gynaecology, obstetrics, and breast cancer. Subject areas include: Chronic conditions (migraine headaches, arthritis, osteoporosis);

\section{Dovepress}

Endocrine and autoimmune syndromes; Sexual and reproductive health; Psychological and psychosocial conditions. The manuscript management system is completely online and includes a very quick and fair peer-review system. Visit http://www.dovepress.com/ testimonials.php to read real quotes from published authors. 